Article

\title{
Luminous Intensity Field Optimization for Antiglare LED Desk Lamp without Second Optical Element
}

\author{
Zhi-Ting Ye ${ }^{1, *} \mathbb{D}$, Chieh Chang ${ }^{2}$, Mao-Chieh Juan ${ }^{3}$ and Kuei-Jung Chen ${ }^{4}$ \\ 1 Department of Mechanical Engineering, Advanced Institute of Manufacturing with High-Tech Innovations, \\ National Chung Cheng University, 168, University Rd., Min-Hsiung, Chia-Yi 62102, Taiwan \\ 2 Department of Hospital and Health Care Management. Chia-Nan University of Pharmacy, No.60, Sec. 1, \\ Erren Rd., Rende Dist. Tainan 71710, Taiwan; Jaychang68@gmail.co \\ 3 Department of Electro-Optical Engineering, National United University, 2, Lienda, Miaoli 26063, Taiwan; \\ moujay.ruan@gmail.com \\ 4 Department of Materials Science and Engineering, National United University, 2, Lienda, Miaoli 26063, \\ Taiwan; chen_kueijun@nuu.edu.tw \\ * Correspondence: imezty@ccu.edu.tw
}

Received: 11 March 2020; Accepted: 7 April 2020; Published: 10 April 2020

\begin{abstract}
This study proposes a model of a light module with an optimized luminous intensity field for realizing an antiglare light-emitting diode (LED) desk lamp without a second optical element. We simulated different luminous intensity field profiles to analyze the unified glare rating (UGR) and illumination uniformity performance of a desk lamp. The spatial effect of UGR and the illumination uniformity affect eye comfort. The light module was set to different beam angles without a second optical element, louver structure, and reflective element on the luminaire to compare different UGRs and uniformity values for evaluating human eye comfort. The simulation and experimental results indicated that the luminous intensity curve for a beam angle of $90^{\circ}$ achieved an illumination uniformity of $80 \%$ and a UGR of 18.1 at a height of $45 \mathrm{~cm}$, thus realizing a human-friendly antiglare desk lamp.
\end{abstract}

Keywords: light-emitting diode; unified glare rating; antiglare; desk lamp; second optical element

\section{Introduction}

Light-emitting diodes (LEDs) offer advantages such as high efficiency, a high color-rendering index, energy saving, and environmental protection [1-3]. Therefore, they have been widely applied as the light source in desk lamps [4]. However, the luminous flux and unified glare rating (UGR) of desk lamps affect the comfort of the human eye. At the same luminous flux, a smaller light-emitting area has more serious glare problems. Converting a point light source into a light source with a larger, uniform area and adjusting the appropriate light beam angle can suppress UGRs effectively. Because of their light-emitting characteristics, LEDs are point light sources; therefore, they must first be converted into planar light sources.

Some studies have discussed how to convert LED point light sources into a planar light source to reduce the UGR index. In 2015, a hollow light guide with edge-lit LED sources was proposed. A hollow-type planar light source with reflecting, scattering, and multiple point light sources along at least one side plane was proposed to build a planar light source module [5]. A hollow light guide comprising LEDs with an asymmetric light field was proposed to transform an LED point light source into a planar light source without a light guide plate, so that it had $40 \%$ lower weight than a solid light guide module [6]. Another study developed a light guide plate with LEDs with an asymmetric light distribution and a light guide plate with a printed diffusion reflection on the bottom surface to 
achieve a circular large-area light source [7]. A light source module with adjustable diffusion includes an array of illumination elements and a light-diffusing material [8]. A light regulation device includes a first light guide structure with an incident light, a second light guide structure with a light-emitting surface, and a light deflection sheet with a first light deflection layer [9]. In industrial applications, some design methods have been proposed to achieve sufficient and uniform luminance over the entire surface — which is irradiated with light—of a light guide plate, and to achieve uniform luminance over an entire range to be irradiated with light [10-12]. A linear light source device was developed with a rectangular-shaped wiring substrate and a wiring pattern on it, and multiple light-emitting elements were arranged on the wiring substrate to achieve a linear light source device and a planar light source device [13]. A planar light source device with an illumination apparatus was developed to realize a planar light source device that can provide planar, uniform, and high-quality planar illumination [14-17].

The UGR value is an important function for evaluating the suitability of desk lamp lighting for the human eye. The lighting-driven spatial light field distribution can affect the perception of the human eye. Overly bright light sources can cause glare, which may impair visual efficiency. Luminaire designers use multiple structures to reduce glare; for instance, reflective matrix bars can improve the UGR and illumination uniformity and simultaneously achieve adequate illuminance. However, this causes a large loss in luminaire efficiency. Therefore, we proposed luminous intensity field optimization for an antiglare LED desk lamp without a second optical element. This study used DIALux evo 8.2 for simulations.

\section{Glare Definition and Spatial Characteristics}

The glare calculation method recommended by the International Commission on Illumination (CIE) was used to combine the Einhorn and Hopkinson formulas and the Guth position parameter. The calculated uniform glare index was used to predict the visual impact on the environment from the glare of a light source based on human factors. According to CIE 55-1983 and CIE 119-1995, the CIE Glare Index (CGI) of indoor lighting fixtures is defined as follows $[18,19]$

$$
C G I=8 \log \left[2 \cdot \frac{1+\frac{E_{d}}{500}}{E_{d}+E_{i}} \cdot \sum \frac{L_{a}{ }^{2} \omega_{a}}{P_{a}^{2}}\right]
$$

where $E_{d}$ is the direct vertical illumination of human eyes (direct vertical illuminance, lux), $E_{i}$ is the indirect illumination on human eyes (indirect illuminance, lux), $L_{a}$ is the brightness value of a single lamp in the line of sight of the human eye (luminance, nit), $\omega_{a}$ is the solid angle formed by a single lamp on human eyes (steradian, sr), and $P_{a}$ is the Guth Position Index of a single luminaire. The Guth position refers to the position of the lamp and the human eye, and it is defined as follows

$$
\frac{1}{P_{a}}=\frac{d^{2} E X P}{d^{2}+1.5 d+4.6}+0.12(1-E X P)
$$

where EXP is defined as follows

$$
\operatorname{EXP}=e^{\left(\frac{-0.18^{S^{2}}}{d}+\frac{0.011 S^{3}}{d}\right)}
$$

where $d$ is the horizontal distance between the luminaire and the human eye divided by the vertical height between the luminaire and the human eye (forward distance of source/height), and $S$ is the horizontal distance between the luminaire and the vertical line of sight divided by the vertical height between the luminaire and the human eye (sideways distance of source/height). 
CIE 117-1995 also defines another uncomfortable glare index called the UGR that considers the effect of background brightness on glare. Therefore, the parameters of the background luminance of the environment $L_{b}$ are added as follows [20]

$$
U G R=8 \log \left[\frac{0.25}{L_{b}} \sum\left(\frac{L^{2} \omega_{i}}{p^{2}}\right)\right]
$$

where 8 gives UGR numbers that optimize and range from approximately 5 to 40 , the logarithm $(\log )$ is used because human eyes react logarithmically to light, and $\Sigma$ shows that the equation includes all the fittings located within the area, where $L_{b}$ is defined as follows:

$$
L_{b}=\frac{E_{i n d}}{\pi}
$$

Here, $L_{b}$ is the value of the background luminance in $\mathrm{cd} / \mathrm{m}^{2}, E_{\text {ind }}$ is the vertical indirect illuminance of the viewer's eye, and $L$ is defined as follows:

$$
L=\frac{I}{A_{p}}
$$

Here, $L$ is the luminance value of the luminous parts of each luminaire in the direction of the viewer's eye in $\mathrm{cd} / \mathrm{m}^{2}, I$ is the luminaire's luminance, $A_{p}$ is the project area, and $\omega_{i}$ is defined as follows:

$$
\omega_{i}=\frac{A_{p}}{r^{2}}
$$

Here, $\omega_{i}$ is the solid angle of the luminous parts of each luminaire on the viewer's eye in steradian (sr), $r$ is the distance from the light source to the viewer's eyes, and $p$ is the Guth position index for each individual luminaire that corresponds to its displacement from the line of sight and is related to the horizontal and tangent function of the observer to the light source.

Uniformity is calculated as follows [21]:

$$
\text { Uniformity }=\frac{\text { minimum illuminance }(l u x)}{\text { average illuminance }(l u x)}
$$

\section{Simulation of UGR and Illumination Uniformity}

\subsection{Spatial Characteristics}

We set up a desk lamp for a study desk, as illustrated in Figure 1a, with a desk length and desk width of $L 0$ and $W 0$, respectively. $P 1$ and $P 2$ indicate the positions of the desk lamp and observer, respectively; the distance between them is $D 1$. As shown in Figure 1b, the observer and desk lamp are positioned at $P 3$ and $P 4$ above the desk surface at height $\mathrm{H} 1$ and height $H 2$. The calculation object has a length and width of $L 1$ and $W 1$, respectively. The observer on the edge of the desk indicates a student in front of the desk. We set the desk lamp rotation angles as $+\theta$ and $-\theta$. Table 1 shows the simulation setup parameters.

The simulation setup parameters of symbol and characteristics are shown in Table 2. 


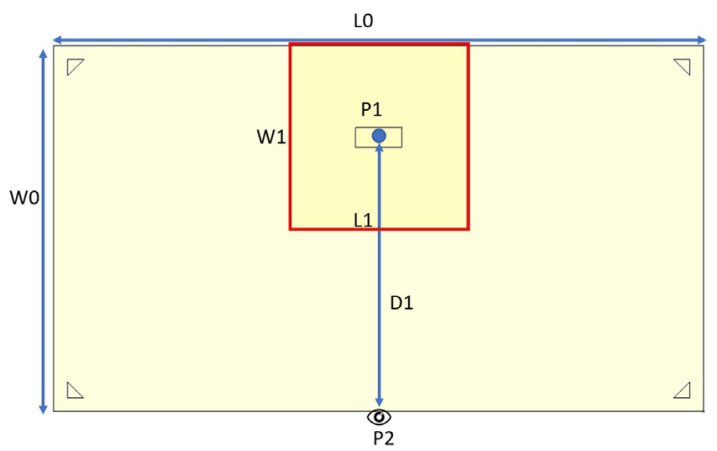

(a)

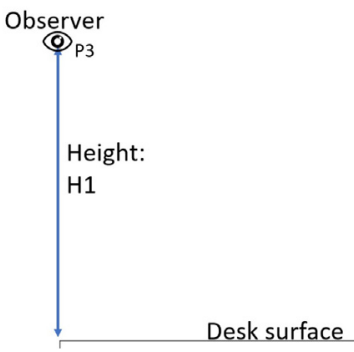

(b)

Figure 1. Simulation spatial characteristic in software: (a) desk luminaire plan and (b) side view of desk lamp on study desk.

Table 1. Simulation setup parameters.

\begin{tabular}{cc}
\hline Symbol & Characteristics \\
\hline L0 (desk length) & $140 \mathrm{~cm}$ \\
W0 (desk width) & $80 \mathrm{~cm}$ \\
L1 (calculation object length) & $40 \mathrm{~cm}$ \\
W1 (calculation object width) & $40 \mathrm{~cm}$ \\
D1 (the distance between desk lamp and observer) & $60 \mathrm{~cm}$ \\
$H 1$ (the distance between desk surface and observer) & $40 \mathrm{~cm}$ \\
\hline
\end{tabular}

Table 2. DIALux simulation parameters.

\begin{tabular}{cc}
\hline Specifications & Characteristics \\
\hline Luminous flux & 800 lumens \\
Reflection factors of desk surface & $50 \%$ \\
Desk lamp height $(H 2)$ & $45 \mathrm{~cm}$ \\
\hline
\end{tabular}

\subsection{UGR and Uniformity at Beam Angles of $70-120^{\circ}$ at the Same Height}

Table 2 shows the DIALux simulation parameters. It has a luminous flux of $800 \mathrm{~lm}$, reflection factors of desk surface of $50 \%$ and desk lamp height of $45 \mathrm{~cm}$.

Table 3 shows the variation in the UGR with the beam angle of 70-120. We can vary the beam angles without changing the height of the desk lamp on the study desk to compare the corresponding UGR values.

Table 3. Relationship between unified glare rating (UGR) and beam angle.

\begin{tabular}{ccc}
\hline Beam Angle Degree & Desk Lamp Height $\left.H_{2} \mathbf{( c m}\right)$ & UGR \\
\hline 70 & 45 & $<10$ \\
80 & 45 & 10 \\
90 & 45 & 17.4 \\
100 & 45 & 22.6 (fail) \\
110 & 45 & 27.1 (fail) \\
120 & 45 & $>30$ (fail) \\
\hline
\end{tabular}

Figure 2 shows the isoline and color illumination map (lux) of uniformity under different beam angle conditions. 


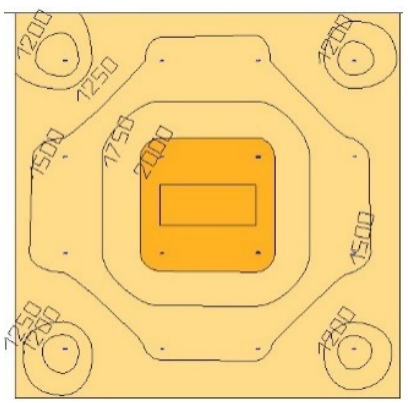

(a)

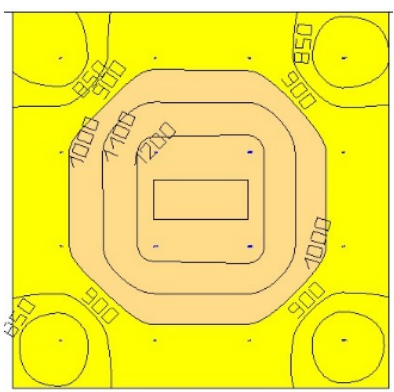

(d)

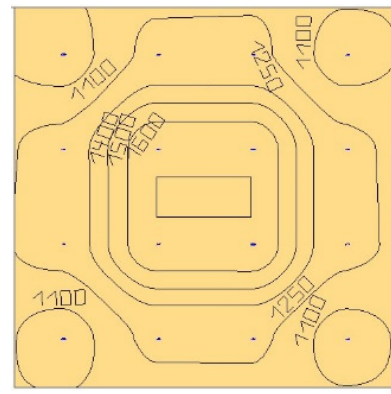

(b)

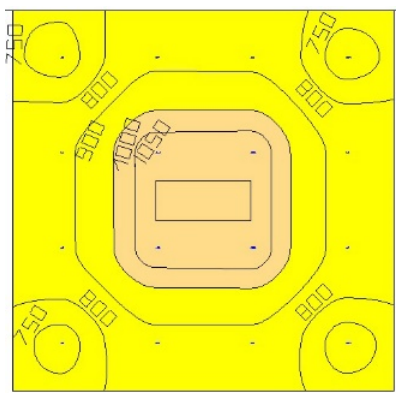

(e)

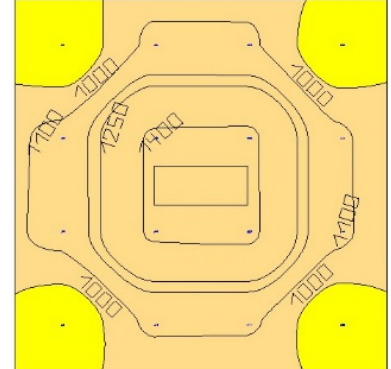

(c)

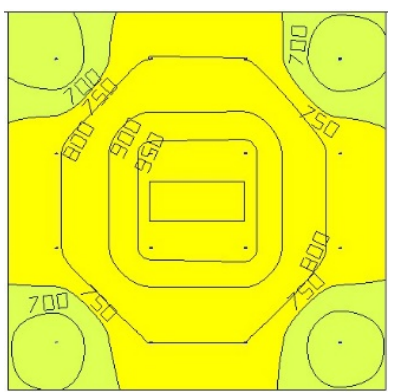

(f)

Figure 2. Isoline and color illumination map (lux) under different beam angles: (a) $70^{\circ}$, (b) $80^{\circ}$, (c) $90^{\circ}$, (d) $100^{\circ}$, (e) $110^{\circ}$, and (f) $120^{\circ}$.

Figure 2 shows the isoline and color illumination map under different beam angles: $70^{\circ}, 80^{\circ}, 90^{\circ}$, $100^{\circ}, 110^{\circ}$, and $120^{\circ}$ respectively. Figure $2 \mathrm{c}$ shows the simulation result with a desk lamp beam angle of $90^{\circ}$ in the illumination isoline. This result indicates that the 1000-1400 lux isoline is distributed in most of the space and the $>1000$ lux isoline is at the four corners, as indicated by the orange and yellow regions, respectively. The lux isoline changes with a variation in the beam angle. When the beam angle increases, the isoline distribution becomes more uniform because the light exposure range is wider.

The simulation results were used to calculate the illumination and uniformity for different beam angles. As shown in Table 4, the uniformity had its maximum value of 0.83 for a beam angle of $120^{\circ}$. The average illumination was 1139 lux for a beam angle of $90^{\circ}$; this was higher than the values for beam angles of $100-120^{\circ}$. The illumination value is greater than 500 lux to comply with the regulations for a desk lamp for a study desk.

Table 4. Illumination and uniformity for beam angles of $70-120^{\circ}$.

\begin{tabular}{ccccccc}
\hline & \multicolumn{7}{c}{ Beam Angle } \\
\cline { 2 - 6 } & $\mathbf{7 0}^{\circ}$ & $\mathbf{8 0}^{\circ}$ & $\mathbf{9 0}^{\circ}$ & $\mathbf{1 0 0}^{\circ}$ & $\mathbf{1 1 0}^{\circ}$ & $\mathbf{1 2 0}^{\circ}$ \\
\hline Average flux (lux) & 1571 & 1322 & 1139 & 998 & 891 & 805 \\
Minimum flux (lux) & 1175 & 1032 & 911 & 810 & 731 & 666 \\
Maximum flux (lux) & 2053 & 1676 & 1414 & 1220 & 1074 & 959 \\
Uniformity & 0.75 & 0.78 & 0.8 & 0.81 & 0.82 & 0.83 \\
\hline
\end{tabular}

Figure 3 shows the luminous intensity profile for beam angles of $70-120^{\circ}$.

The luminous intensity field for a beam angle of $70^{\circ}$ was the narrowest; with an increase in the beam angle, the luminous intensity field widened. In the determination of the UGR, a narrow beam angle outperformed a wide beam angle. By contrast, in the determination of the illumination uniformity, a wide beam angle was superior to a narrow beam angle. Tables 3 and 4 show the homogenized UGR and uniformity values, respectively. 


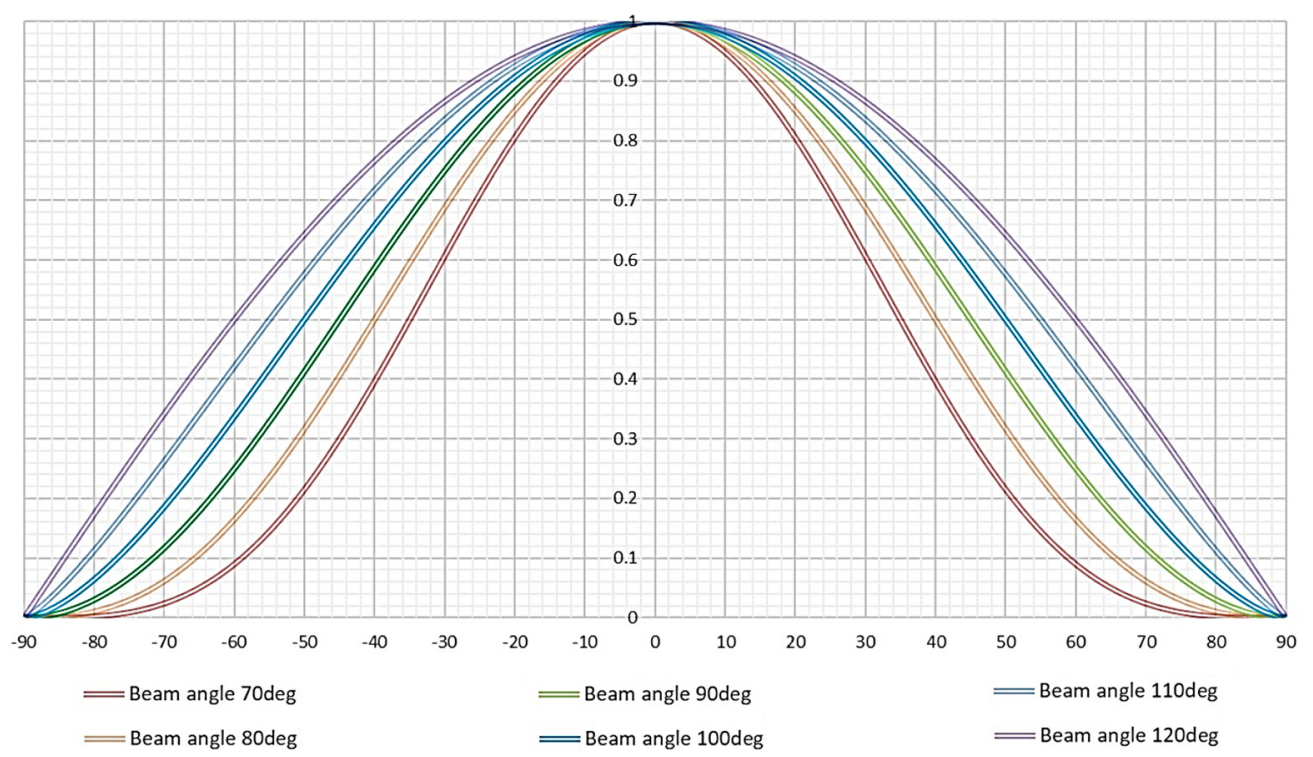

Figure 3. Luminous intensity field profile for beam angles of $70-120^{\circ}$.

Figure 4 shows the relationship between UGR and uniformity at various beam angles. For a beam angle of $90^{\circ}$, the UGR is less than the threshold value of 19 , and the uniformity is higher than that for beam angles of $70^{\circ}$ and $80^{\circ}$; this is similar to the uniformity for beam angles of $100^{\circ}$ and $110^{\circ}$. Therefore, considering the UGR and the uniformity values simultaneously, the best beam angle is $90^{\circ}$.

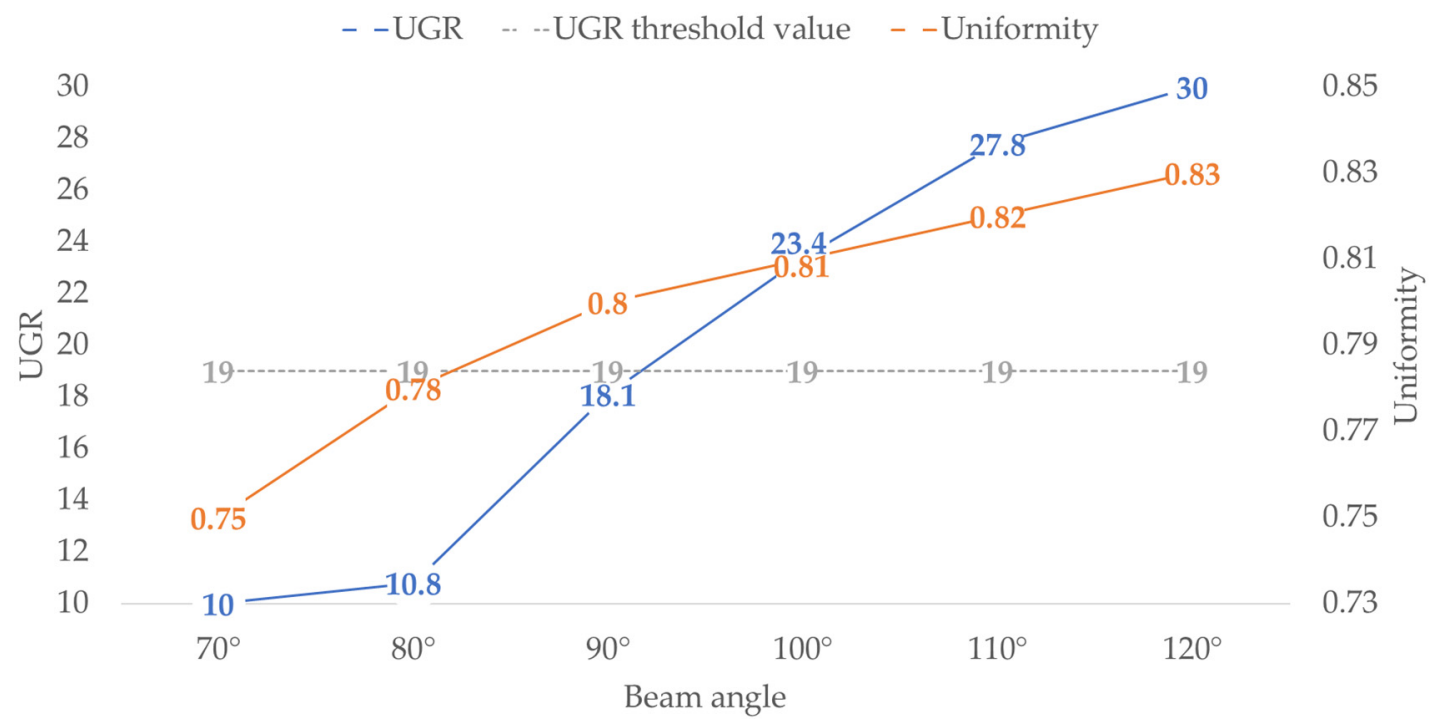

Figure 4. UGR and uniformity for beam angles of 70-120 .

\subsection{UGR and Uniformity at Beam Angle of $90^{\circ}$ for Different Desk Lamp Heights}

Table 5 shows the variation in the UGR with the desk lamp height for a beam angle of $90^{\circ}$. We can modulate desk lamp height without changing the beam angle of the desk lamp to compare UGR.

Figure 5 shows the isoline and color illumination map (lux) of uniformity for different desk lamp heights with a beam angle of $90^{\circ}$. 
Table 5. Relationship between UGR and desk lamp height.

\begin{tabular}{c}
\hline Beam Angle Degree \\
90 \\
90 \\
90 \\
90 \\
90 \\
90 \\
90 \\
90 \\
90 \\
90 \\
90 \\
\\
\end{tabular}

(a)

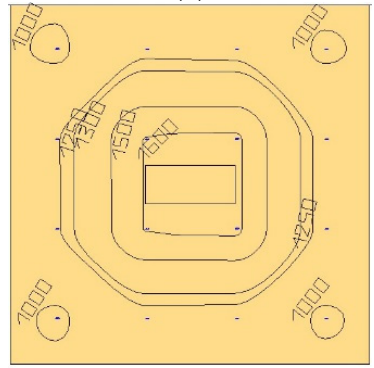

(d)

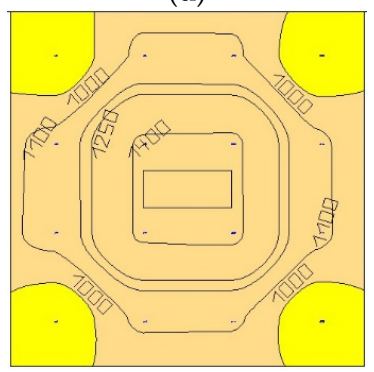

(g)

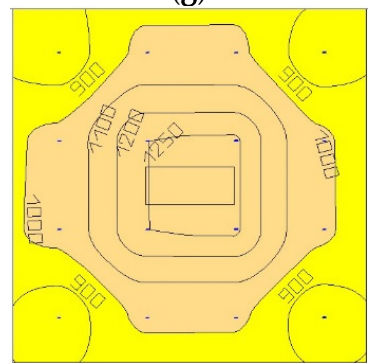

(j)

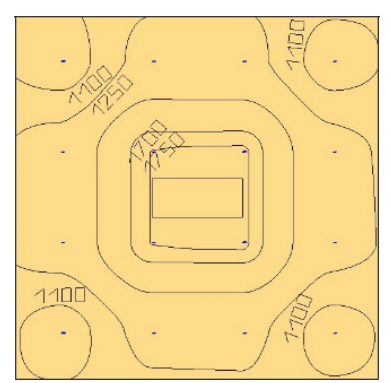

(b)

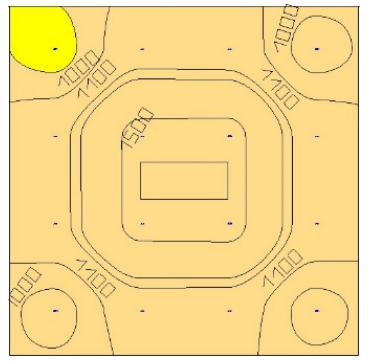

(e)

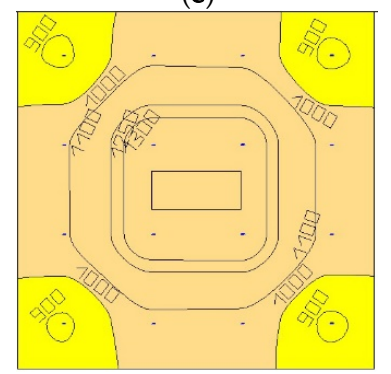

(h)

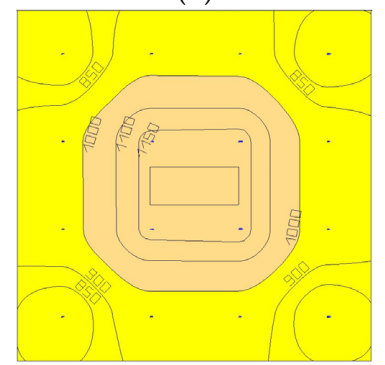

(k)

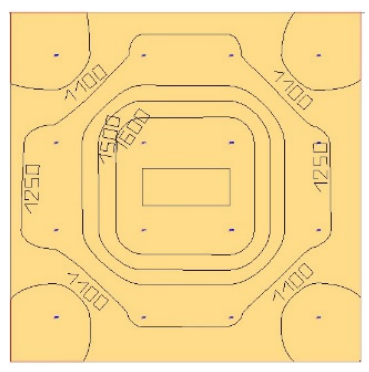

(c)

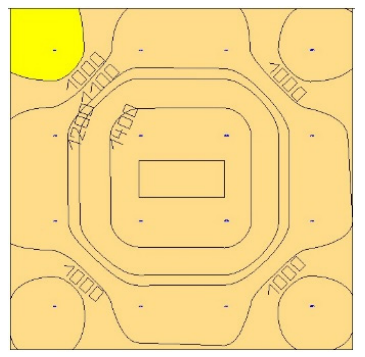

(f)

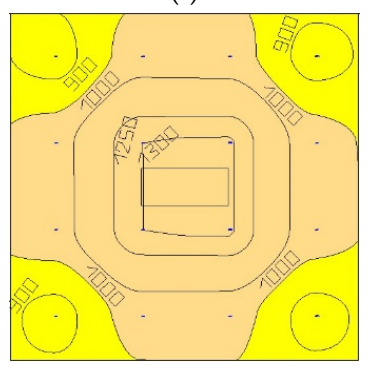

(i)

Figure 5. Isoline and color illumination map (lux) with different light source heights: (a) $35 \mathrm{~cm}$, (b) $40 \mathrm{~cm}$, (c) $41 \mathrm{~cm}$, (d) $42 \mathrm{~cm}$, (e) $43 \mathrm{~cm}$, (f) $44 \mathrm{~cm}$, (g) $45 \mathrm{~cm}$, (h) $46 \mathrm{~cm}$, (i) $47 \mathrm{~cm}$, (j) $48 \mathrm{~cm}$, and (k) $50 \mathrm{~cm}$. 
Figure 5 shows the isoline and color illumination map (lux) with different light source heights: 35 , $40,41,42,43,44,45,46,47,48$, and $50 \mathrm{~cm}$, respectively. Figure $5 \mathrm{~g}$ shows the lux isolines simulated using a $45 \mathrm{~cm}$ high desk lamp; the 1000-1400 lux isoline is distributed in most of the space and the $>1000$ lux isoline is at the four corners, as indicated by the orange and yellow regions, respectively.

The simulation results were used to calculate the illumination uniformity for different desk lamp heights. To comply with the regulations for a study desk, a desk lamp height of $50 \mathrm{~cm}$ resulted in the highest uniformity, and a height of $35 \mathrm{~cm}$ resulted in the highest average flux.

Tables 5 and 6 present the homogenized UGR and uniformity values, respectively. Figure 6 shows the variation in the UGR and the uniformity with the desk lamp height. For a beam angle of $90^{\circ}$ and desk lamp height of $45 \mathrm{~cm}$, the UGR is less than the threshold value of 19 , and the uniformity is higher than that for heights of $35,40,41,42,43$, and $44 \mathrm{~cm}$.

Table 6. Illumination and uniformity for different desk lamp heights of $35-50 \mathrm{~cm}$.

\begin{tabular}{cccccccccccc}
\hline & \multicolumn{10}{c}{ Desk Lamp Height $\mathbf{H 2})$} \\
\cline { 2 - 12 } & $\mathbf{3 5} \mathbf{~ c m}$ & $\mathbf{4 0} \mathbf{~ c m}$ & $\mathbf{4 1} \mathbf{~ c m}$ & $\mathbf{4 2} \mathbf{~ c m}$ & $\mathbf{4 3} \mathbf{~ c m}$ & $\mathbf{4 4} \mathbf{~ c m}$ & $\mathbf{4 5} \mathbf{~ c m}$ & $\mathbf{4 6} \mathbf{~ c m}$ & $\mathbf{4 7} \mathbf{~ c m}$ & $\mathbf{4 8} \mathbf{~ c m ~}$ & $\mathbf{5 0} \mathbf{~ c m}$ \\
\hline Average flux (lux) & 1624 & 1354 & 1307 & 1262 & 1262 & 1178 & 1139 & 1102 & 1066 & 1033 & 969 \\
Minimum flux (lux) & 1144 & 1030 & 1007 & 983 & 959 & 935 & 911 & 889 & 866 & 845 & 803 \\
Maximum flux (lux) & 2239 & 1757 & 1679 & 1607 & 1538 & 1474 & 1414 & 1357 & 1304 & 1254 & 1161 \\
Uniformity & 0.7 & 0.76 & 0.77 & 0.78 & 0.79 & 0.79 & 0.8 & 0.81 & 0.81 & 0.82 & 0.83 \\
\hline
\end{tabular}

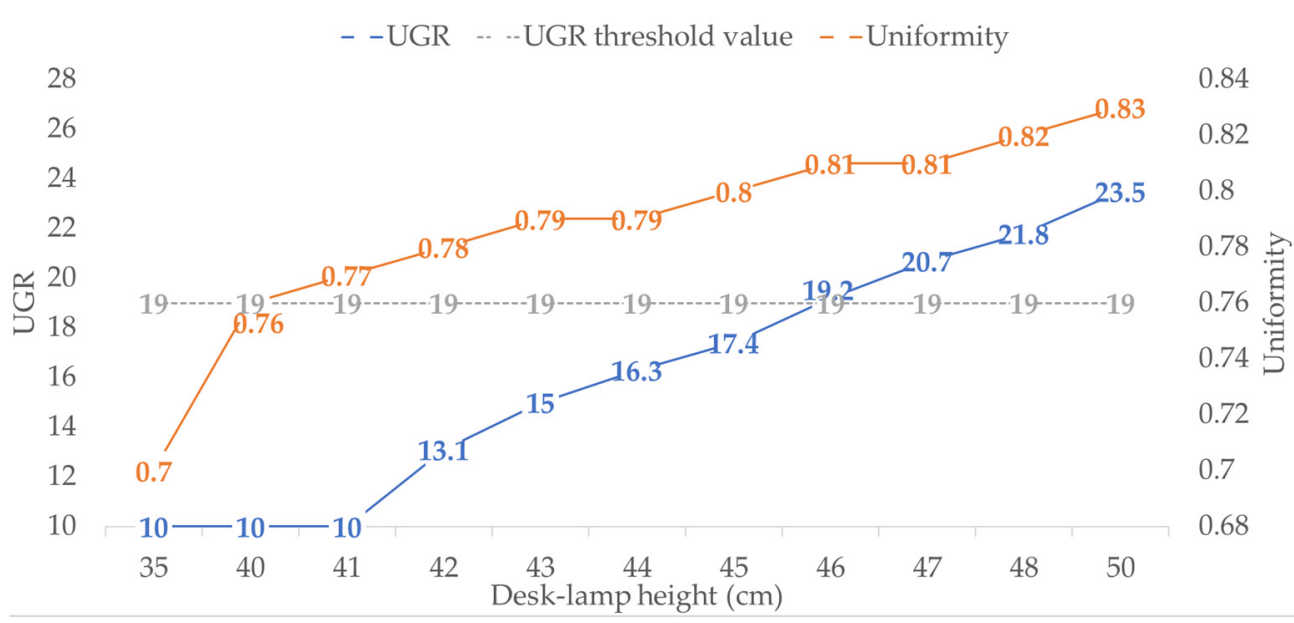

Figure 6. UGR and uniformity for desk lamp heights of $35-50 \mathrm{~cm}$.

3.4. UGR and Uniformity for Beam Angle of $90^{\circ}$ and Desk Lamp Height of $45 \mathrm{~cm}$ with Different Rotation Angles

Table 7 shows the UGR for a beam angle of $90^{\circ}$ and desk lamp height of $45 \mathrm{~cm}$ with different rotation angles. We can modulate the desk lamp rotation angle without changing the beam angle and height of the desk lamp on the study desk to compare UGR.

Figure 7 shows the isoline and color illumination map (lux) of the uniformity for a beam angle of $90^{\circ}$ and desk lamp height of $45 \mathrm{~cm}$ with different rotation angles. 
Table 7. Relationship between UGR and rotation angle.

\begin{tabular}{cccc}
\hline Beam Angle Degree & Desk Lamp Height $H_{2} \mathbf{( c m )}$ & Rotation Angle $(\boldsymbol{\theta})$ & UGR \\
\hline 90 & 45 & $5^{\circ}$ & $<10$ \\
90 & 45 & $4^{\circ}$ & $<10$ \\
90 & 45 & $3^{\circ}$ & 12.1 \\
90 & 45 & $2^{\circ}$ & 14.4 \\
90 & 45 & $1^{\circ}$ & 16.1 \\
90 & 45 & $0^{\circ}$ & 17.4 \\
90 & 45 & $-1^{\circ}$ & 19.4 (fail) \\
90 & 45 & $-2^{\circ}$ & 21.2 (fail) \\
90 & 45 & $-3^{\circ}$ & 22.6 (fail) \\
90 & 45 & $-4^{\circ}$ & 23.6 (fail) \\
90 & 45 & $-5^{\circ}$ & 24.5 (fail) \\
\hline
\end{tabular}

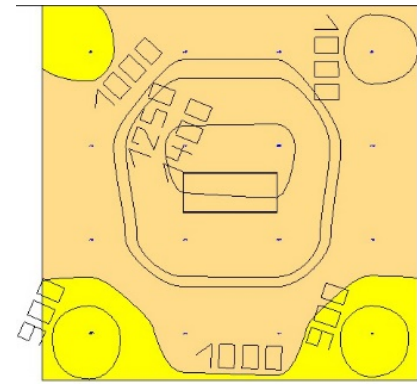

(a)

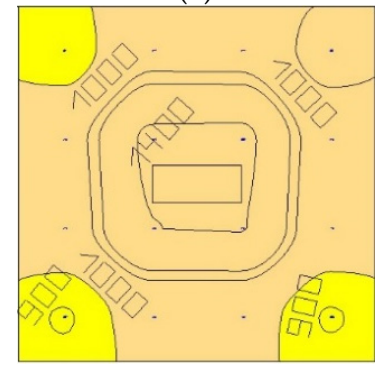

(d)

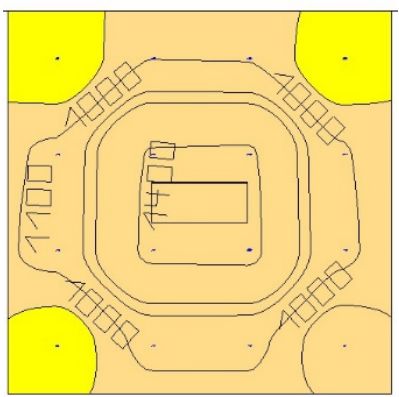

(g)

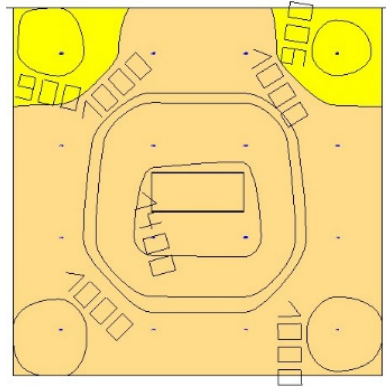

(j)

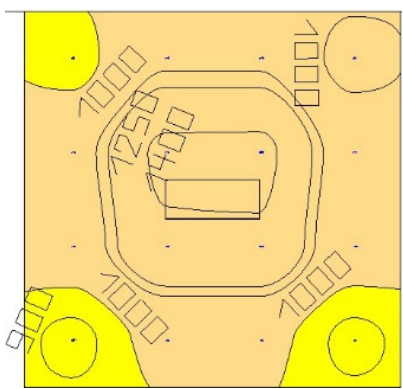

(b)

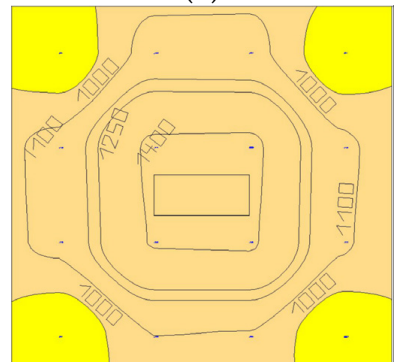

(e)

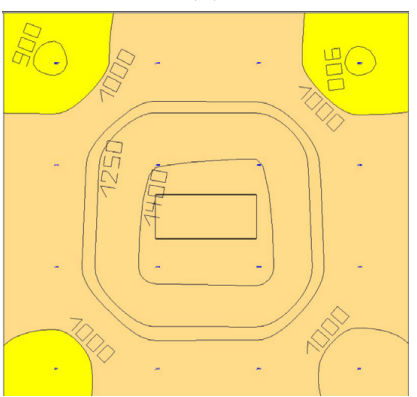

(h)

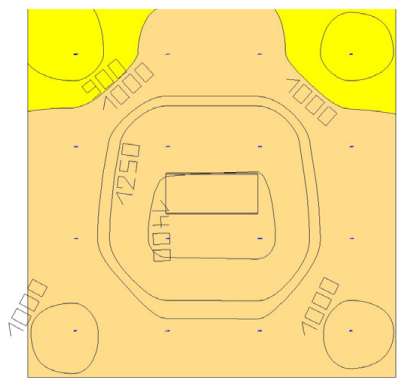

(k)

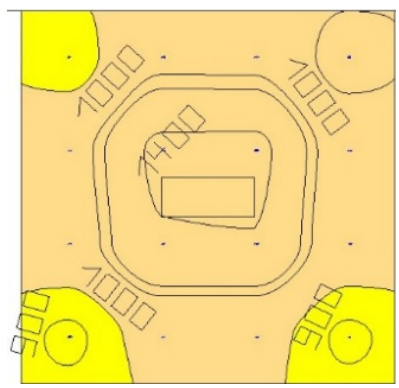

(c)

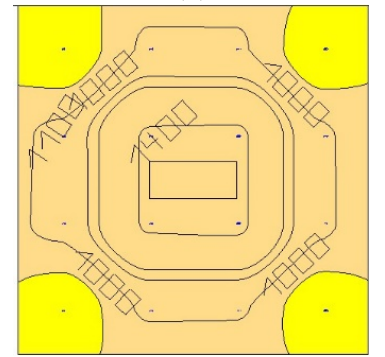

(f)

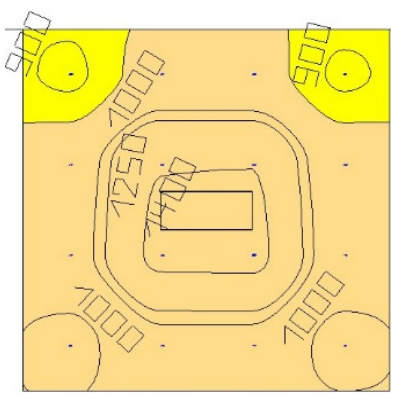

(i)

Figure 7. Isoline and color illumination map (lux) with different desk lamp rotation angles: (a) $5^{\circ}$, (b) $4^{\circ}$, (c) $3^{\circ}$, (d) $2^{\circ}$, (e) $1^{\circ},(\mathbf{f}) 0^{\circ},\left(\right.$ g) $-1^{\circ},(\mathbf{h})-2^{\circ},(\mathbf{i})-3^{\circ},(\mathbf{j})-4^{\circ}$, and $(\mathbf{k})-5^{\circ}$. 
Figure 7 shows isoline and color illumination map (lux) with different desk lamp rotation angles $5^{\circ}, 4^{\circ}, 3^{\circ}, 2^{\circ}, 1^{\circ}, 0^{\circ},-1^{\circ},-2^{\circ},-3^{\circ},-4^{\circ}$, and $-5^{\circ}$, respectively. Figure $7 \mathrm{f}$ shows the lux isolines simulated using a desk lamp rotation angle of $0^{\circ}$; the 1000-1400 lux isoline and the $>1000$ lux isoline are at the four corners, similar to the situation resulting from a rotation angle of $1^{\circ}$, as indicated by the orange and yellow regions, respectively.

The simulation results were used to calculate the illumination and uniformity for different desk lamp rotation angles, as shown in Table 8 . For a desk lamp rotation angle of $0^{\circ}$, the uniformity achieved the maximum value of 0.8 .

Table 8. Illumination and uniformity for different desk lamp heights of $35-50 \mathrm{~cm}$.

\begin{tabular}{cccccccccccc}
\hline & \multicolumn{10}{c}{ Rotation Angle $(\boldsymbol{\theta})$} \\
\cline { 2 - 12 } & $\mathbf{5}^{\circ}$ & $\mathbf{4}^{\circ}$ & $\mathbf{3}^{\circ}$ & $\mathbf{2}^{\circ}$ & $\mathbf{1}^{\circ}$ & $\mathbf{0}^{\circ}$ & $\mathbf{- 1}^{\circ}$ & $\mathbf{- 2}^{\circ}$ & $-\mathbf{3}^{\circ}$ & $\mathbf{- 4}^{\circ}$ & $\mathbf{5}^{\circ}$ \\
\hline Average flux (lux) & 1133 & 1136 & 1138 & 1139 & 1139 & 1139 & 1139 & 1139 & 1138 & 1136 & 1133 \\
Minimum flux (lux) & 853 & 866 & 879 & 892 & 902 & 911 & 902 & 892 & 879 & 866 & 853 \\
Maximum flux (lux) & 1429 & 1428 & 1427 & 1424 & 1419 & 1414 & 1419 & 1424 & 1427 & 1428 & 1429 \\
Uniformity & 0.75 & 0.76 & 0.77 & 0.78 & 0.79 & 0.8 & 0.79 & 0.78 & 0.77 & 0.76 & 0.75 \\
\hline
\end{tabular}

For the determination of the illumination and uniformity, a rotation angle of $0^{\circ}$ was better than other rotation angles. Tables 7 and 8 show the homogenized UGR and uniformity values, respectively. Figure 8 shows the variation in the UGR and the uniformity with the rotation angle. For a rotation angle of $0^{\circ}$, the UGR was less than the threshold value of 19 , and the uniformity was higher than that for the other rotation angles.

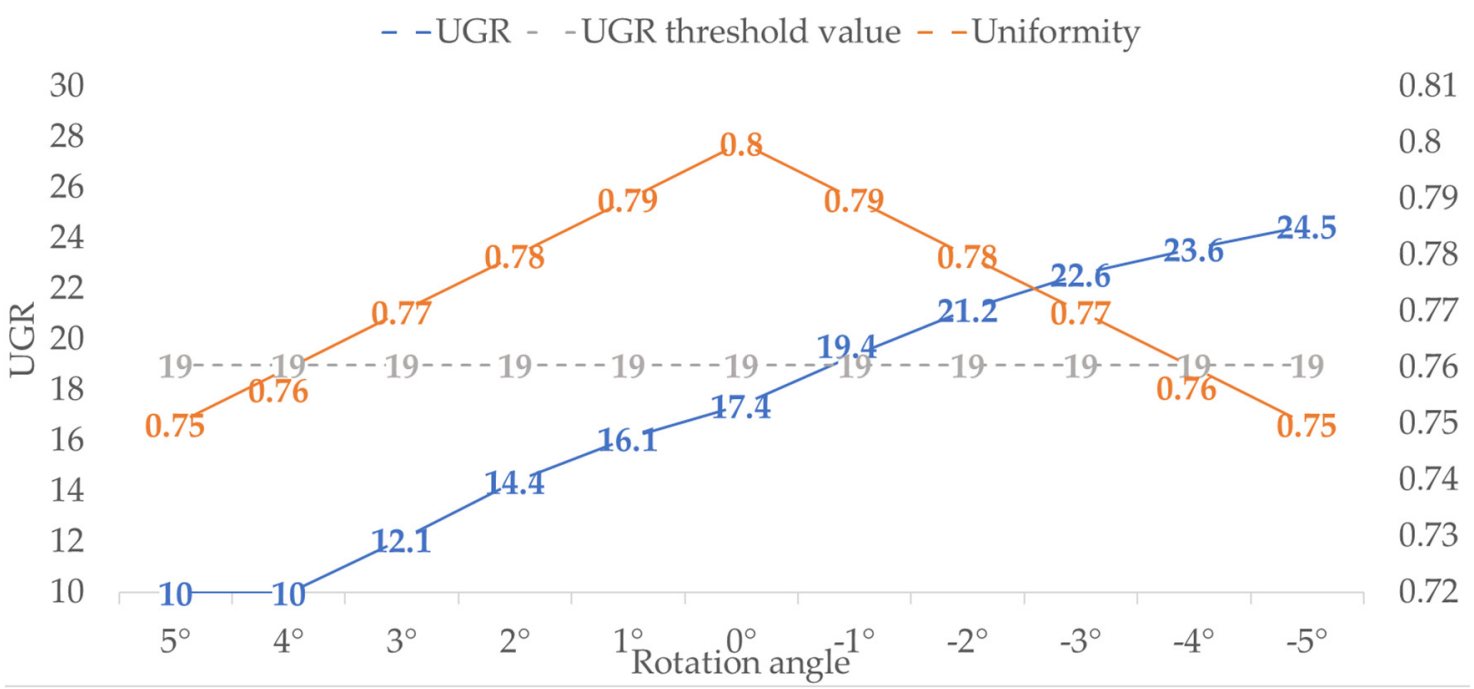

Figure 8. UGR and uniformity for a desk lamp height of $45 \mathrm{~cm}$ and rotation angles of $5^{\circ}$ to $-5^{\circ}$.

The simulation results indicate that the rotation of the desk lamp has a great effect on the glare value, and the glare value exceeds the threshold of 19 for a rotation angle of $-1^{\circ}$ to $-5^{\circ}$.

\section{Experimental Results}

Figure 9 shows a side view of the structure of the desk lamp module. It contains a microstructure diffuser, a brightness enhancement film (BEF), a light guide, a reflective sheet at the bottom, and two LED strips on opposite sides of the light guide. The desk lamp has a width of $42.5 \mathrm{~mm}$, height of $12 \mathrm{~mm}$, and length of $100 \mathrm{~mm}$. The LED model used was Lextar PC35H11, the color temperature of $4000 \mathrm{~K}$ and a color-rendering index of 80 was used. 


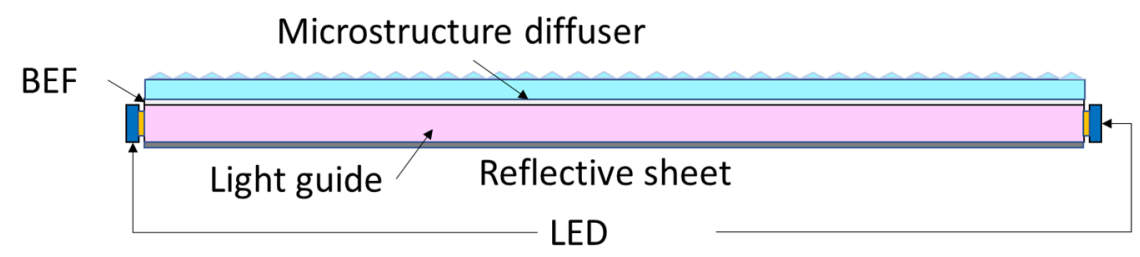

Figure 9. Side view of structure of the desk lamp.

Figure 10 shows the illumination map of the desk lamp module when it was (a) shut down and (b) in operation.

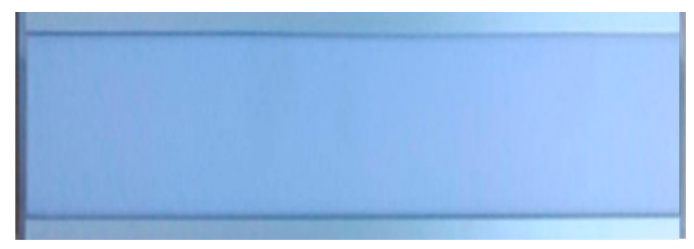

(a) Desk lamp module shut down

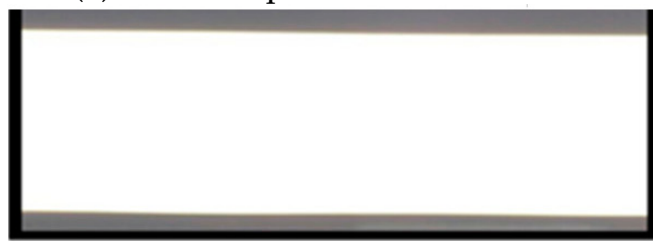

(b) Desk lamp module in operation

Figure 10. Illumination map when the desk lamp module was (a) shut down and (b) in operation.

Figure 11 shows that the illumination values at heights of $0.27,0.36$, and $0.45 \mathrm{~m}$ were 3491,2128 , and 1414 lux, respectively, for a beam angle of $90^{\circ}$. The horizontal coordinate axis represents the illuminance and the vertical coordinate axis represents the distance from the light source.

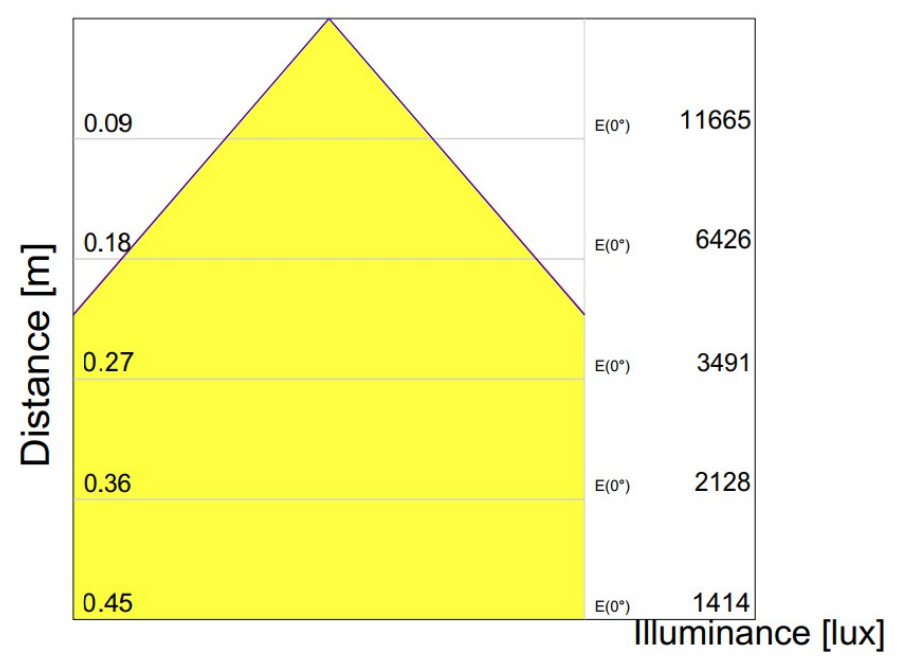

Figure 11. Illumination values at different heights for a beam angle of $90^{\circ}$.

Table 9 shows a comparison between the simulated and the measured illumination values. The result indicates good agreement between the two sets of values.

Table 10 shows a comparison between the simulated and the measured illumination values at the corners of the object area. The result indicates good agreement between the two sets of values. 
Table 9. Comparison between simulated and measured illumination values.

\begin{tabular}{ccc}
\hline $\begin{array}{c}\text { Measuring Distance } \\
(\mathbf{m})\end{array}$ & $\begin{array}{c}\text { Simulated Center Illumination Value } \\
\text { (lux) }\end{array}$ & $\begin{array}{c}\text { Measured Center Illumination Value } \\
(\text { lux })\end{array}$ \\
\hline 0.27 & 3491 & 3428 \\
0.36 & 2128 & 2094 \\
0.45 & 1414 & 1394 \\
\hline
\end{tabular}

Table 10. Comparison between simulated and measured illumination values at the corners of the object area with a desk lamp height of $45 \mathrm{~cm}$.

\begin{tabular}{ccc}
\hline $\begin{array}{c}\text { Measurement Coordinates } \\
\text { (Distance from Point P1) } \mathbf{x}, \mathbf{y}(\mathbf{c m})\end{array}$ & $\begin{array}{c}\text { Simulated Center Illumination } \\
\text { Value (Lux) }\end{array}$ & $\begin{array}{c}\text { Measured Center Illumination } \\
\text { Value (lux) }\end{array}$ \\
\hline $\mathrm{x}-11, \mathrm{y}-12$ & 1048 & 1032 \\
$\mathrm{x}-11, \mathrm{y}+12$ & 1050 & 1029 \\
$\mathrm{x}+12, \mathrm{y}-12$ & 1040 & 1020 \\
$\mathrm{x}+12, \mathrm{y}+12$ & 1069 & 1046 \\
\hline
\end{tabular}

\section{Conclusions}

Taking account of human factors, this study proposed modulation of the light-emitting field of a desk lamp without using a second optical element, louver structure, or second lens on the luminaire to reduce glare-related effects and maintain illumination uniformity in a reading range. The simulation results demonstrate that the light module in the desk lamp should ideally have a beam angle of $90^{\circ}$; the corresponding UGR is less than 19 and illumination uniformity is more than 0.8 . The experimental results obtained using the prototype achieved good agreement with the simulation results. This light model can be used to design a desk lamp lighting plan with a UGR of 18.1 and uniformity of 0.8 and to obtain an average illumination value of 1394 lux at a height of $45 \mathrm{~cm}$. Overall, this study proposes a model of a light module with an optimized luminous intensity field for realizing an antiglare light-emitting diode (LED) desk lamp without a second optical element complying with CNS 16048:2018 C4585 regulations.

Author Contributions: Z.-T.Y., original concept provider, organized and wrote the manuscript. Z.-T.Y., C.C. and K.-J.C. were responsible for data and optical measurements. Z.-T.Y. and M.-C.J. simulation and optimized design. All authors have read and agreed to the published version of the manuscript.

Funding: This research received no external funding.

Conflicts of Interest: The authors declare no conflict of interests.

\section{References}

1. Son, C.-G.; Yi, J.-H.; Gwag, J.-S.; Kwon, J.H.; Park, G.-J. Improvement of Color and Luminance Uniformity of the Edge-Lit Backlight Using the RGB LEDs. J. Opt. Soc. Korea 2011, 15, 272-277. [CrossRef]

2. Huang, Y.-S.; Luo, W.-C.; Wang, H.-C.; Feng, S.-W.; Kuo, C.-T.; Lu, C.-M. How Smart LEDs Lighting Benefit Color Temperature and Luminosity Transformation. Energies 2017, 10, 518. [CrossRef]

3. Tsao, J.Y.; Coltrin, M.E.; Crawford, M.H.; Simmons, J.A. Solid-State Lighting: An Integrated Human Factors, Technology, and Economic Perspective. Proc. IEEE 2010, 98, 1162-1179. [CrossRef]

4. Chen, Y.-S.; Lin, C.-Y.; Yeh, C.-M.; Kuo, C.-T.; Hsu, C.-W.; Wang, H.-C. Anti-glare LED lamps with adjustable illumination light field. Opt. Express 2014, 22, 5183-5195. [CrossRef] [PubMed]

5. Ye, Z.T.; Kuo, H.-C.; Chen, C.-H. Thin hollow light guide for high-efficiency planar illuminator. Appl. Opt. 2015, 54, E23-E29. [CrossRef] [PubMed]

6. Ye, Z.T.; Chen, C.L.; Chen, L.-C.; Tien, C.-H.; Nguyen, H.T.; Wang, H.-C. Hollow Light Guide Module Involving Mini Light-Emitting Diodes for Asymmetric Luminous Planar Illuminators. Energies 2019, 12, 2755. [CrossRef]

7. Ye, Z.T.; Pai, Y.; Chen, C.-H.; Kuo, H.-C.; Chen, L.-C. A Light Guide Plate That Uses Asymmetric Intensity Distribution of Mini-LEDs for the Planar Illuminator. Crystals 2019, 9, 141. [CrossRef] 
8. Fournier, F.R.; Alaimo, A.M.; Lee, S.S.; Scepanovic, M.; Weber, A.G. Light Source Module with Adjustable Diffusion. U.S. Patent 9,894,257,B2, 13 February 2015.

9. Teng, T.C.; Sun, C.H.; Xu, S.G. Light Regulation Device for Light Deflection and Backlight Module Having the Same. U.S. Patent 1,037,187,8B1, 6 August 2018.

10. Dohan, P.; Jaehyeok, K.; Eunseok, K.; Dawoon, J. Light Source Module and Planar Light Source Device Including the Same. U.S. Patent 1,025,446,2B2, 9 April 2019.

11. Itaya, H. Planar Light Source Device and Liquid Crystal Display Apparatus. U.S. Patent 1,049,581,0B2, 3 December 2019.

12. Itoh, Y.; Manabu, O.; Motoki, T. Edge-Light Type Planar Light Source Device. U.S. Patent 9,244,213,B2, 26 January 2016.

13. Ito, Y. Linear Light Source Device and Planar Light Source Device. U.S. Patent 9,022,633,B2, 5 May 2015.

14. Sato, E.; Kenji, F.; Hiroyasu, S.; Rihito, S. Planar Light Source Device and Illumination Apparatus. U.S. Patent 8,911,133,B2, 9 September 2014.

15. Hideki, K.; Yuhki, I. Linear Light Source Device and Planar Light Source Device. U.S. Patent 9,316,781,B2, 19 April 2016.

16. Yasuo, W.; Tomonari, Y.; Kenji, Y. Light Guide, Manufacturing Method of Light Guide, Optical Shutter, and Planar Light-Source Device. U.S. Patent 9,507,072,B2, 29 November 2016.

17. Takahiko, U.; Hiroshi, K. Light Reflector, and Planar Light Source Device and Illuminating Device Using the Light Reflector. U.S. Patent 8,950,920,B2, 10 February 2015.

18. CIE 55:1983; International Commission on Illumination (CIE): Vienna, Austria, 1983.

19. CIE 119-1995; International Commission on Illumination (CIE): Vienna, Austria, 1995.

20. CIE 117-1995; International Commission on Illumination (CIE): Vienna, Austria, 1995.

21. Lighting of Indoor Work Places, ISO CIE 8995, 2nd ed.; International Commission on Illumination (CIE): Vienna, Austria, 2002.

(C) 2020 by the authors. Licensee MDPI, Basel, Switzerland. This article is an open access article distributed under the terms and conditions of the Creative Commons Attribution (CC BY) license (http://creativecommons.org/licenses/by/4.0/). 